\title{
sciendo
}

\section{THE EFFECT OF RUMINAL FLUID PH ON MILK FATTY ACIDS COMPOSITION IN CATTLE*}

\author{
Jolanta Komisarek $^{1 \star}$, Barbara Stefańska ${ }^{2,3}$, Włodzimierz Nowak ${ }^{2}$ \\ ${ }^{1}$ Department of Animal Breeding and Product Quality Assessment, Poznań University of Life Sciences, Złotniki, Słoneczna 1, \\ 62-002 Suchy Las, Poland \\ ${ }^{2}$ Department of Animal Nutrition, Poznań University of Life Sciences, Wołyńska 33, 60-637 Poznań, Poland \\ ${ }^{3}$ Department of Grassland and Natural Landscape Sciences, Poznań University of Life Sciences, Dojazd 11, 60-632 Poznań, Poland \\ •Corresponding author: jolanta.komisarek1@up.poznan.pl
}

\begin{abstract}
The present study aimed to evaluate the effects of ruminal fluid pH on the fatty acids (FA) profile of bovine milk. The experiment was performed on 250 Polish Holstein-Friesian cows reared in 11 commercial high-yielding dairy farms. Ruminal fluid samples were collected by rumenocentesis, and fat and FA concentrations in milk were analyzed by Fourier transform infrared spectroscopy. According to ruminal fluid pH, cows were categorized into three pH groups: high pH (pH > 5.8), moderate pH (pH 5.8-5.6), and low pH (pH < 5.6). Milk produced by low-rumen $\mathrm{pH}$ cows had a decreased fat content as compared to milk from moderate- and high-rumen $\mathrm{pH}$ cows $(\mathrm{P} \leq \mathbf{0 . 0 5})$. Moreover, milk from low-rumen $\mathbf{p H}$ cows was characterized by the lowest level of short-chain FA (SCFA; P $\leq 0.05$ ), and consequently, the highest medium-chain FA to SCFA ratio (P $\leq \mathbf{0 . 0 1})$. The regression analysis showed that these traits explained a small proportion of rumen pH variance, which makes them unreliable indicators of subacute ruminal acidosis (SARA) in dairy cows. However, despite the extensive variability in milk fat composition observed in this study, the effect of ruminal pH on SCFA in all the analyzed herds showed the same trend. Future research aimed to identify SARA biomarkers should therefore be conducted using techniques that allow detection of more individual FA in milk, including SCFA.
\end{abstract}

Key words: dairy cows, Fourier transform infrared spectroscopy, milk fatty acids composition, ruminal acidosis, short-chain fatty acids

Fat is the most variable component of bovine milk, and its composition largely determines the nutritional value of milk for human consumption. The total fat content and the fatty acids (FA) profile of milk are influenced by several factors, the main being cattle breed, individual variability, and stage of lactation (Gottardo et al., 2017; Hanuš et al., 2018). Milk FA profile is also closely related to the feeding of dairy cows and thus provides considerable information on the metabolic and health status of animals (Colman et al., 2010; Vranković et al., 2017).

It is a common practice to feed high-producing dairy cows with highly fermentable diets, which, however, may lead to the decrease in ruminal $\mathrm{pH}$ and to the development of subacute ruminal acidosis (SARA). SARA is one of the most common digestive disorders in dairy herds, with a huge negative effect on the economy and animal welfare (Kleen and Cannizzo, 2012). The current methods to diagnose SARA, based on the measurement of ruminal $\mathrm{pH}$ by using a stomach oral probe or rumenocentesis, are invasive and not very accurate because of diurnal fluctuations in pH (Duffield et al., 2004). High concentrate diets, which can lead to SARA, were also found to modify the FA profile of milk (Enjalbert et al., 2008; Colman et al., 2010). The possible mechanisms of this phenomenon include changes in ruminal fermentation and biohydrogenation patterns and, consequently, in the supply of regulators and substrates for milk fat synthesis (Colman et al., 2012; Abdela, 2016) as well as alteration in the expression of genes involved in lipogenesis in both the mammary gland (Tao et al., 2015) and liver (Xu et al., 2018). Previous research has shown that milk FA have potential to serve as biomarkers of SARA in dairy cows (Colman et al., 2010; Jing et al., 2018). However, most experiments evaluating the effects of SARA on milk fat composition were performed on a small number of cows of the same parity and originating from the same herd, and the decrease in $\mathrm{pH}$ of ruminal fluid typically resulted from feeding cows with acidosis-inducing experimental diets (Enjalbert et al., 2008; AlZahal et al., 2010; Guo et al., 2013). The FA profile of milk is usually determined by gas chromatography (GC). This technique is very accurate, but expensive and time-consuming, which prevents its application for large-scale routine measurements. In the present study, the concentrations of major

\footnotetext{
*The research was partially supported by a grant financed by the Polish Federation of Cattle Breeders and Dairy Farmers (no. 70/2014/U) and the statutory funds (no. 506.569.04.00) of the Faculty of Veterinary Medicine and Animal Science, Poznań University of Life Sciences.
} 
FA in milk were determined by Fourier transform infrared spectroscopy (FT-IR), which has been shown to have great potential for regular determination of fat composition in milk (De Marchi et al., 2014).

The present study aimed to evaluate the effect of ruminal fluid $\mathrm{pH}$ on FA and FA groups in the milk of cows from Polish high-yielding dairy herds, varying in their parity and days in milk (DIM). We anticipate that the findings of this study will provide further information on the potential of FT-IR-predicted milk fat components in identifying cows at risk of SARA.

\section{Material and methods}

\section{Ethics statement}

The research was performed in accordance with the "Act on the protection of animals used for scientific purpose" of the Republic of Poland and was approved by the Local Ethical Committee in Poznań, Poland, decision no. 32/2014.

\section{Animals}

The study included 250 Polish Holstein-Friesian cows from 11 high-yielding dairy farms under routine milk performance recording conducted by the Polish Federation of Cattle Breeders and Dairy Farmers (PFCBDF). All animals were kept in loose housing systems and fed total mixed rations. Further details on the experimental farms are available in Stefańska et al. (2017 a, b, 2018, 2020). From each herd, 18 to 26 cows were selected. They were in early and mid-lactation stage (40 to 150 DIM), their 305-day milk yields were 10 050-12 $041 \mathrm{~kg}$, and their parities ranged from 1 to 6 . All cows were free from clinical mastitis, metritis, and hoof diseases.

\section{Ruminal fluid sampling and analyses}

Ruminal fluid samples were collected 4 to $6 \mathrm{~h}$ after morning feeding by rumenocentesis as described in Stefańska et al. (2017 a, b, 2018, 2020). Ruminal fluid $\mathrm{pH}$ measurements of all samples were performed immediately after collection by using a CP-104 pH me- ter (Elmetron, Poland). The cows were then categorized into three $\mathrm{pH}$ groups, according to the classification of Nordlund and Garrett (1994): high pH (>5.81), moderate $\mathrm{pH}(5.8-5.6)$, and low $\mathrm{pH}(<5.6)$. Table 1 shows the average ruminal $\mathrm{pH}$ in these groups as well as in cows representing different herds, parities, and stages of lactation.

\section{Milk sampling and analyses}

Milk samples were collected from each cow in the morning and afternoon milking sessions during regular milk recording test days. Fat and FA concentrations were measured in the Laboratory of PFCBDF by FT-IR using MilkoScan FT 6000 equipment with diamond cuvettes (Foss, Hillerød, Denmark). The FT-IR absorption spectra consisted of 1060 infrared frequencies (wave numbers) ranging from 925 to $5008 \mathrm{~cm}^{-1}$, which represent infrared light absorption through the milk samples. FA traits, expressed as $\mathrm{g} / 100 \mathrm{~g}$ of fat, included 4 individual FA, namely C14:0, C16:0, C18:0, and C18:1, and 8 groups, namely saturated FA (SFA), unsaturated FA (UFA), monounsaturated FA (MUFA), polyunsaturated FA (PUFA), trans-unsaturated FA (TRANSFA), short-chain FA (SCFA), medium-chain FA (MCFA), and long-chain FA (LCFA). The MCFA to SCFA ratio (MCFA/SCFA), the SFA to UFA ratio (SFA/UFA), and the $\mathrm{C} 18$ desaturation index (DI18) were also calculated; the latter was determined as a proportion of $\mathrm{C} 18: 1$ to the sum of $\mathrm{C} 18: 0$ and C18:1, multiplied by 100 .

\section{Statistical analyses}

Data were analyzed using SAS statistical software version 9.4 (SAS, 2014). The effects of the studied factors on the concentrations of fat and FA in milk were tested by analysis of variance (ANOVA) using the PROC GLM procedure. The statistical model included the effects of ruminal $\mathrm{pH}$ group (high $\mathrm{pH}$, moderate $\mathrm{pH}$, low $\mathrm{pH}$ ), farm number (from 1 to 11 ), number of parity $(1,2$, $\geq 3$ ), and DIM group ( $<90$ days, $\geq 90$ days). For parameters showing significant differences, Duncan's multiple range test was used to compare mean values. Additionally, the PROC REG procedure was used to determine the

Table 1. The average ruminal $\mathrm{pH}( \pm$ SEM) for cows representing different farms, $\mathrm{pH}$ groups, parities, and DIM groups

\begin{tabular}{|c|c|c|c|c|c|c|c|}
\hline \multicolumn{2}{|c|}{ Group } & Ruminal $\mathrm{pH}$ & $\mathrm{P}$ & \multicolumn{2}{|c|}{ Group } & Ruminal pH & $\mathrm{P}$ \\
\hline \multirow[t]{11}{*}{ Farm } & 1 & $6.05 \pm 0.08$ & $<0.001$ & Ruminal pH group & High $\mathrm{pH}$ & $6.37 \pm 0.04$ & $<0.001$ \\
\hline & 2 & $5.94 \pm 0.09$ & & & Moderate $\mathrm{pH}$ & $5.71 \pm 0.01$ & \\
\hline & 3 & $6.09 \pm 0.08$ & & & Low $\mathrm{pH}$ & $5.44 \pm 0.02$ & \\
\hline & 4 & $6.33 \pm 0.07$ & & Parity & 1 & $6.12 \pm 0.06$ & 0.060 \\
\hline & 5 & $5.66 \pm 0.06$ & & & 2 & $5.98 \pm 0.06$ & \\
\hline & 6 & $5.70 \pm 0.06$ & & & $\geq 3$ & $6.17 \pm 0.05$ & \\
\hline & 7 & $5.81 \pm 0.09$ & & DIM & $<90$ days & $6.14 \pm 0.05$ & 0.166 \\
\hline & 8 & $6.03 \pm 0.09$ & & & $\geq 90$ days & $6.04 \pm 0.05$ & \\
\hline & 9 & $7.08 \pm 0.11$ & & & & & \\
\hline & 10 & $6.07 \pm 0.07$ & & & & & \\
\hline & 11 & $6.22 \pm 0.07$ & & & & & \\
\hline
\end{tabular}


relationships between the concentrations of fat and FA in milk and the ruminal $\mathrm{pH}$ value. In all analyses, the effects were considered significant at $\mathrm{P} \leq 0.05$, and the standard error of the mean (SEM) was adopted as a measure of error.

\section{Results}

Figure 1 shows the average concentrations of fat and FA in the milk of cows originating from 11 dairy farms included in this study. In the population studied, the farm effect was significant $(\mathrm{P} \leq 0.01)$ for all the analyzed traits.

Table 2 presents the estimated effects of ruminal $\mathrm{pH}$ group, cows' parity, and DIM on the concentration of fat and FA in milk. With the decrease in $\mathrm{pH}$ of ruminal fluid, the concentrations of fat and SCFA decreased $(\mathrm{P} \leq 0.05)$, whereas the MCFA/SCFA ratio increased $(\mathrm{P} \leq 0.01)$. A similar trend for SCFA and MCFA/SCFA was observed in all farms included in the study.

The parity of cows affected PUFA, MCFA, and MCFA/SCFA $(\mathrm{P} \leq 0.01)$ and TRANSFA $(\mathrm{P} \leq 0.05$; Table $2)$. With the advancing age of cows, PUFA and TRANSFA increased, and MCFA and MCFA/SCFA declined. The stage of lactation influenced eight FA traits. Cows in the earlier lactation phase (DIM ranging from 40 to 89) were characterized by higher concentrations of $\mathrm{C} 18: 0$ $(\mathrm{P} \leq 0.01)$, LCFA, and MUFA $(\mathrm{P} \leq 0.05)$ in milk as compared to cows in the later lactation phase (DIM from 90 to 150). The opposite effects were observed for C14:0,
MCFA, and MCFA/SCFA ( $\mathrm{P} \leq 0.01), \mathrm{C} 16: 0$, and SFA/ UFA $(\mathrm{P} \leq 0.05)$

Table 3 shows the results of the regression analysis for the effect of $\mathrm{pH}$ of ruminal fluid on milk fat and FA concentrations. A significant relationship was found between ruminal $\mathrm{pH}$ and C16:0, PUFA, SCFA, MCFA, and MCFA/SCFA $(\mathrm{P} \leq 0.01)$. However, all regression equations had low R-squared values, varying between 0.029 and 0.215 .

\section{Discussion}

In the current study, low-rumen $\mathrm{pH}$ cows produced milk with lower fat percentage than cows from moderate- and high-rumen $\mathrm{pH}$ groups. The decreased milk fat content has often been associated with SARA (Enjalbert et al., 2008; Guo et al., 2013). This is thought to be mainly caused by alterations in ruminal biohydrogenation patterns that lead to the increased production of C18:2 t10, c12 isomer, which is a strong inhibitor of mammary lipid synthesis (Bauman and Grinarii, 2003). However, Sandri et al. (2020) recently showed that experimentally induced SARA decreased fat concentration in milk by other mechanisms such as reduced availability of preformed FA mobilized from the adipose tissue. Low milk fat content was not always observed in cows induced with SARA, possibly because of short-term decrease in ruminal pH (Krause and Oetzel, 2005).

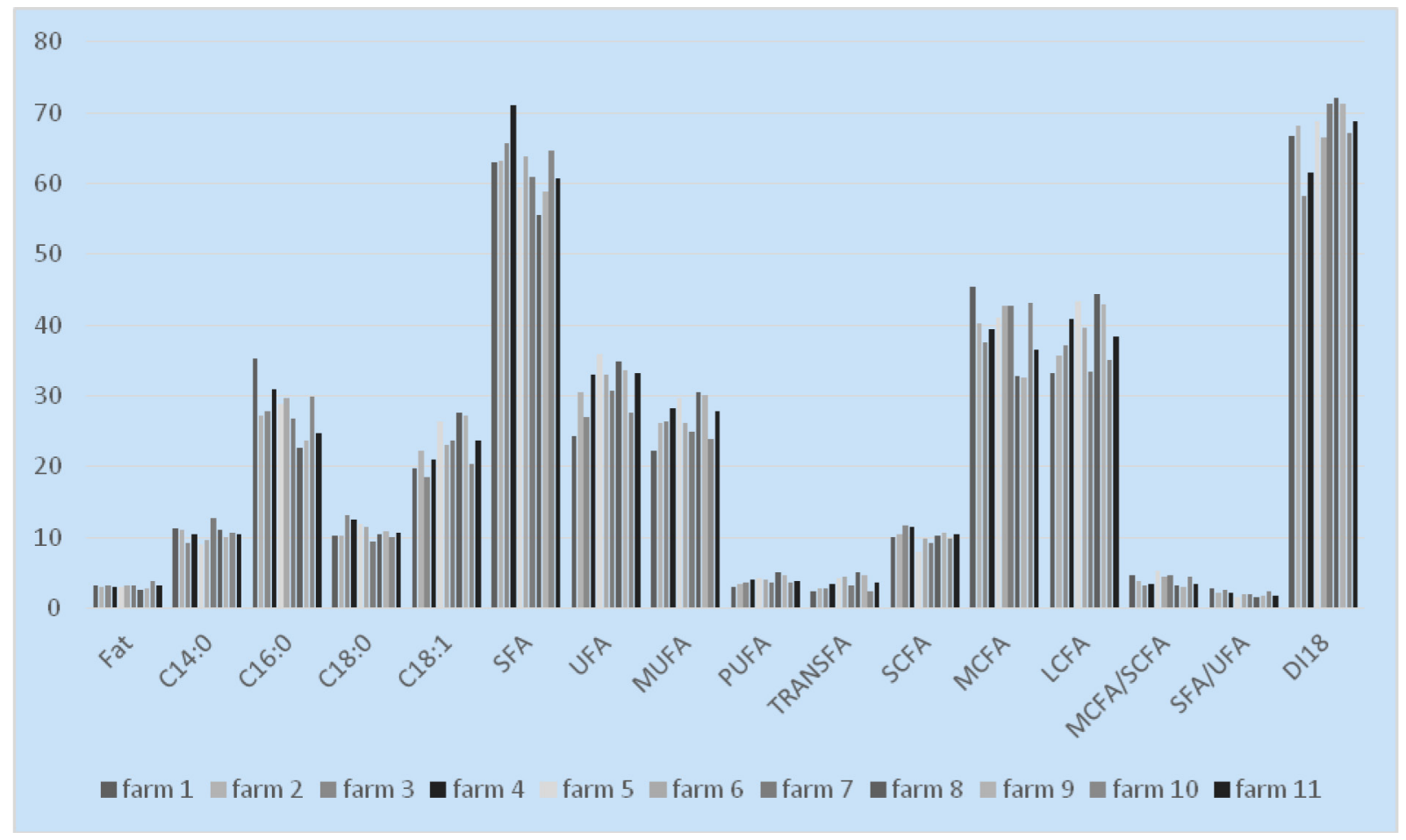

Figure 1. The average concentrations of fat (g/100 $\mathrm{g}$ of milk) and fatty acids (FA; g/100 $\mathrm{g}$ of fat) in milk of Polish Holstein-Friesian cows originating from 11 dairy farms. SFA: saturated FA, UFA: unsaturated FA, MUFA: monounsaturated FA, PUFA: polyunsaturated FA, TRANSFA: transunsaturated FA, SCFA: short-chain FA, MCFA: medium-chain FA, LCFA: long-chain FA, MCFA/SCFA: MCFA to SCFA ratio, SFA/UFA: SFA to UFA ratio, DI18: unsaturation index calculated as $\mathrm{C} 18: 1 /(\mathrm{C} 18: 0+\mathrm{C} 18: 1) \times 100$ 


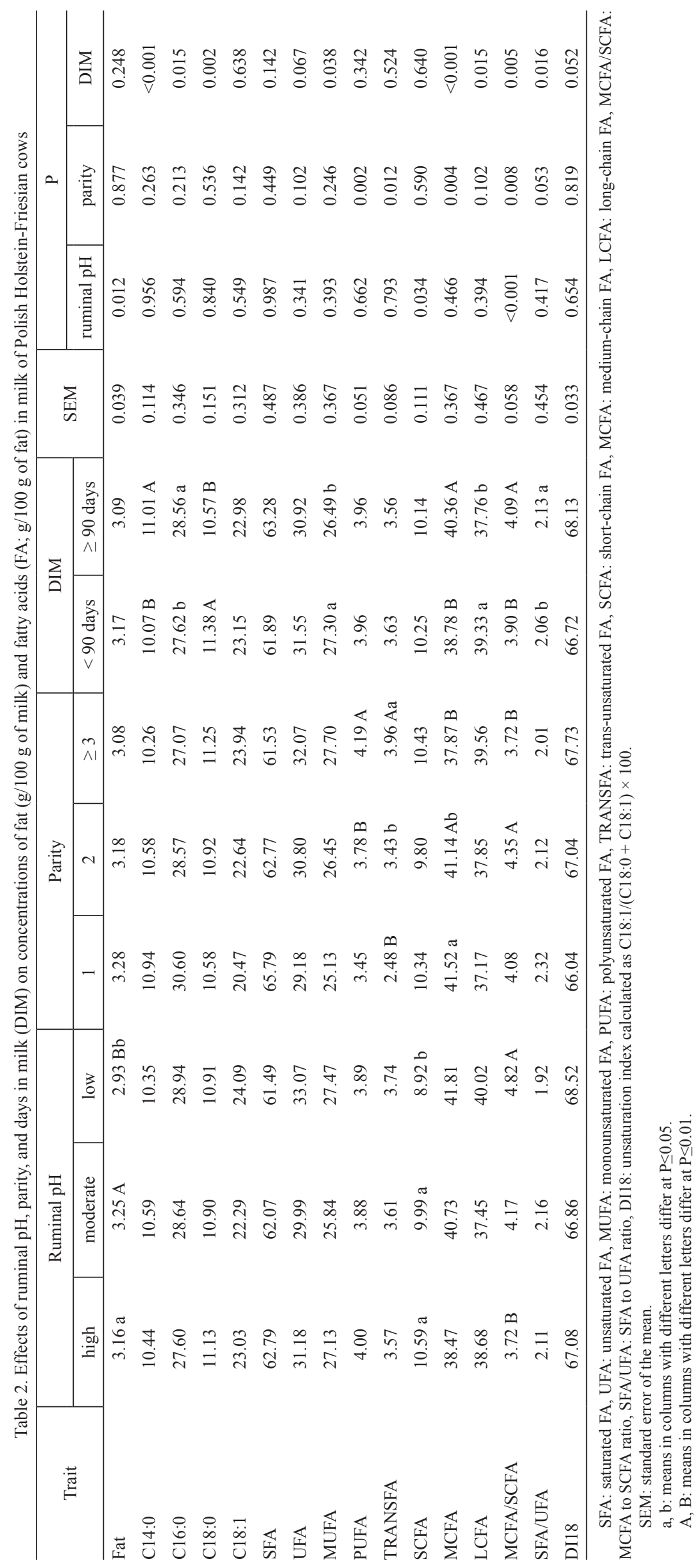


Table 3. Regression analysis of the effect of ruminal fluid $\mathrm{pH}$ on milk concentrations of fat (g/100 g of milk) and fatty acids (FA; g/100 g of fat) in Polish Holstein-Friesian cows

\begin{tabular}{lccccc}
\hline \multicolumn{1}{c}{ Trait } & Coefficient & Intercept & $\mathrm{R}^{2}$ & $\mathrm{P}$ \\
\hline Fat & $\mathrm{NS}$ & $\mathrm{NS}$ & $\mathrm{NS}$ & 0.756 \\
C14:0 & $\mathrm{NS}$ & $\mathrm{NS}$ & $\mathrm{NS}$ & 0.870 \\
C16:0 & -0.017 & 6.567 & 0.029 & 0.007 \\
C18:0 & $\mathrm{NS}$ & $\mathrm{NS}$ & $\mathrm{NS}$ & 0.973 \\
C18:1 & $\mathrm{NS}$ & $\mathrm{NS}$ & $\mathrm{NS}$ & 0.201 \\
SFA & $\mathrm{NS}$ & $\mathrm{NS}$ & $\mathrm{NS}$ & 0.997 \\
UFA & $\mathrm{NS}$ & $\mathrm{NS}$ & $\mathrm{NS}$ & 0.722 \\
MUFA & $\mathrm{NS}$ & $\mathrm{NS}$ & $\mathrm{NS}$ & 0.056 \\
PUFA & 0.138 & 5.555 & 0.043 & 0.001 \\
TRANSFA & $\mathrm{NS}$ & $\mathrm{NS}$ & $\mathrm{NS}$ & 0.089 \\
SCFA & 0.091 & 5.175 & 0.088 & $<0.001$ \\
MCFA & -0.033 & 7.416 & 0.130 & $<0.001$ \\
LCFA & $\mathrm{NS}$ & $\mathrm{NS}$ & $\mathrm{NS}$ & 0.137 \\
MCFA/SCFA & -0.271 & 7.180 & 0.215 & $<0.001$ \\
SFA/UFA & $\mathrm{NS}$ & $\mathrm{NS}$ & $\mathrm{NS}$ & 0.930 \\
DI18 & $\mathrm{NS}$ & $\mathrm{NS}$ & $\mathrm{NS}$ & 0.494 \\
\hline
\end{tabular}

SFA: saturated FA, UFA: unsaturated FA, MUFA: monounsaturated FA, PUFA: polyunsaturated FA, TRANSFA: trans-unsaturated FA, SCFA: short-chain FA, MCFA: medium-chain FA, LCFA: long-chain FA, MCFA SCFA: MCFA to SCFA ratio, SFA/UFA: SFA to UFA ratio; DI18: unsaturation index calculated as $\mathrm{C} 18: 1 /(\mathrm{C} 18: 0+\mathrm{C} 18: 1) \times 100$.

NS: values not shown, as $\mathrm{P}$ was not significant at $5 \%$ level.

Milk fat percentage is generally believed to be a poor predictor of ruminal $\mathrm{pH}$, as it greatly depends on many other nutritional and physiological factors (Lock, 2010). During the first weeks after calving, the effects of SARA on milk fat synthesis may interact with body fat mobilization due to the negative energy balance, which makes it difficult to interpret the milk fat content particularly in early lactation cows (Kleen et al., 2013). In addition, there are other causes of decrease in milk fat content, such as the high level of UFA in the diet (Bauman and Griinari, 2001).

There is growing interest in the use of specific FA as potential indicators of SARA. Milk FA concentrations predicted in this experiment by using the FT-IR method were generally in agreement with those previously determined by GC in the milk of Polish Holstein-Friesian cows (Kuczyńska et al., 2012; Proskura et al., 2019). Some differences observed between the studies (e.g., lower content of C16:0 than that reported by Proskura et al., 2019) could result from different composition of cows' diets as well as different datasets, as we used only high-producing cows that are at the highest risk of developing SARA. The use of different analytical methods might also be a crucial factor. Samková et al. (2020) recently showed that the FT-IR method can be advantageously used, especially for those FA and FA groups that are present in high proportions of the total milk fat. Results for FA present in milk in low proportions should, however, be interpreted with caution, because of lower correlation coefficients between FT-IR and GC values for these traits.
Some authors who analyzed the relationship between SARA and milk FA profile showed that low-rumen $\mathrm{pH}$ can reduce the biohydrogenation process of the C18UFA, leading to higher proportions of certain trans-C18 FA isomers and lower level of C18:0 in milk fat (Enjalbert et al., 2008; Colman et al., 2013; Guo et al., 2013). These findings, in reference to C18:0, were not confirmed in the present study. The increased concentrations of oddand branched-chain FA (OBCFA) in the milk of acidotic cows were also reported (Enjalbert et al., 2008; Colman et al., 2010, 2012; Guo et al., 2013; Jing et al., 2018). The OBCFA are synthesized by the ruminal bacteria, although the occurrence of their post-ruminal production in the mammary gland was also suggested (Vlaeminck et al., 2015). The FT-IR method used in the present study to determine FA composition did not allow detecting individual OBCFA in milk. However, our previous study performed on the same animals showed greater concentrations of propionate and valerate (precursors of odd-chain FA) as well as iso-butyrate and iso-valerate (precursors of branched-chain FA) in the ruminal fluid of acidotic cows as compared to those in healthy cows (Stefańska et al., 2018).

In the present study, SCFA and, consequently, MCFA/ SCFA were the only fat components associated with ruminal $\mathrm{pH}$, and low-rumen $\mathrm{pH}$ cows produced milk with the lowest proportion of SCFA and the highest MCFA/ SCFA ratio. The same trend of effects of ruminal fluid $\mathrm{pH}$ on these traits was observed in all the analyzed farms. Moreover, although MCFA/SCFA was affected by all factors included in this study, SCFA was not influenced by parity and DIM. In previous studies, the effect of SARA on the SCFA group was not analyzed, and its effects on individual short-chain FA were diverse (Enjalbert et al., 2008; Colman et al., 2013; Sandri et al., 2020).

The SCFA are mainly de novo synthesized in the mammary gland from acetate and $\beta$-hydroxybutyrate, which originate from the microbial fermentation of dietary carbohydrates in the rumen. Previously, we showed increased molar concentrations of volatile FA, including acetate and butyrate, in the ruminal fluid of acidotic cows (Stefańska et al., 2018). The reduced level of SCFA in the milk of low-rumen $\mathrm{pH}$ cows might therefore be due to lower expression or activity of enzymes involved in de novo FA synthesis rather than due to deficiency of substrates for their production. This hypothesis is also supported by the findings that lipopolysaccharides derived from the rumen of SARA-affected ruminants decrease the expression of certain genes associated with lipid metabolism (Tao et al., 2015; Xu et al., 2018). On the other hand, milk MCFA, which are also thought to be primarily sourced from post-ruminal de novo synthesis in the mammary gland, were not associated with ruminal $\mathrm{pH}$ groups in the present study, and the regression coefficient indicated an inverse relationship between these parameters. Furthermore, the regression analysis showed that SCFA (as well as MCFA/SCFA, MCFA, PUFA, and C16:0) are unable to stand alone as an indicator of ruminal acidosis, 
as they explain a small proportion of rumen $\mathrm{pH}$ variance (as indicated by R-squared value).

The poor relationship that we observed between ruminal fluid $\mathrm{pH}$ and milk FA profile could result from the use of the FT-IR method, which allowed identifying only a few individual FA in milk. The other reason might be the considerable variability in FA concentrations between herds included in this study, which is most likely due to the different compositions of total mixed ration diets provided in the analyzed farms (Stefańska et al., 2018, 2020). A substantial variation in the average ruminal $\mathrm{pH}$ values and milk FA concentrations was observed between herds, even though only farms similar in terms of cows' milk yield as well as housing and feeding systems were selected for the present study.

Differences in milk FA profile were also noted between cows varying in DIM and parity. Changes in FA composition during lactation are related to a large extent to the body energy balance (Ducháček et al., 2014). Cows in the early lactation stage are typically deficient in energy for up to the first 3 months after calving. In this state, they mobilize adipose tissue, which is particularly rich in LCFA such as C18:1 cis-9 and C18:0 (Hostens et al., 2012). This consequently leads to increased proportions of preformed LCFA in milk at the expense of de novo synthesized SCFA, as observed in this study in 4089 DIM cows as compared to that in 90-150 DIM cows. The content of MUFA decreased as the lactation stage progressed. Similar trends in milk FA concentrations of early and mid-lactation cows were found by Stoop et al. (2009), Gottardo et al. (2017), and Vranković et al. (2017). The results of the current study also suggest that the effects of lactation stage on milk fat composition are not induced by changes in ruminal $\mathrm{pH}$, which was similar in cows varying in DIM.

There are contrasting data in the literature on the effect of parity on milk FA composition in cattle. Some authors found that first lactation cows have lower proportions of MCFA such as C16:0 in their milk as compared to later lactation cows (Craninx et al., 2008; Gottardo et al., 2017); this finding could be explained by the metabolically less active mammary gland of primiparous cows (Miller et al., 2006). In the present study, the most significant effect was observed for the MCFA level, which, however, decreased as cows' parity increased. This could be related to a smaller energy deficit in early lactation primiparous cows than in older animals, as shown by de Vries et al. (1999). On the other hand, individual FA as well as SCFA and LCFA concentrations were not associated with parity in the present study.

\section{Conclusion}

In our present experiment, the milk FA profile determined using the FT-IR method proved to be an unreliable indicator of decreased $\mathrm{pH}$ of the ruminal fluid in dairy cows. Future studies aimed to identify SARA biomarkers should be conducted using techniques that allow detecting more individual FA in milk; the extensive vari- ability in fat composition in milk should be considered between farms similar in cows' productivity and feeding systems. The results of this study indicate that SCFA are particularly interesting as one of the potential indicators of SARA, as SCFA level decreased with the decrease in ruminal $\mathrm{pH}$ in all the analyzed farms, regardless of cows' parity and DIM. However, only high-producing herds and cows were selected for this study; therefore, the results may not be representative for larger dairy cattle population.

\section{References}

Abdela N. (2016). Sub-acute ruminal acidosis (SARA) and its consequence in dairy cattle: a review of past and recent research at global prospective. Achiev. Life Sci., 10: 187-196.

AlZahal O., Or-Rashid M.M., Greenwood S.L., McBride B.W. (2010). Effect of subacute ruminal acidosis on milk fat concentration, yield and fatty acid profile of dairy cows receiving soybean oil. J. Dairy Res., 77: 376-384.

Bauman D.E., Griinari J.M. (2001). Regulation and nutritional manipulation of milk fat: Low-fat milk syndrome. Livest. Prod. Sci., 70: 15-29.

Bauman D.E., Griinari J.M. (2003). Nutritional regulation of milk fat synthesis. Annu. Rev. Nutr., 23: 203-227.

Colman E., Fokkink W.B., Craninx M., Newbold J.R., De Baets B., Fievez V. (2010). Effect of induction of subacute ruminal acidosis on milk fat profile and rumen parameters. J. Dairy Sci., 93: 4759-4773.

Colman E., Tas B., Waegeman W., De Baets B., Fievez V. (2012). The logistic curve as a tool to describe the daily ruminal $\mathrm{pH}$ pattern and its link with milk fatty acids. J. Dairy Sci., 95: 5845-5865.

Colman E., Khafipour E., Vlaeminck B., De Baets B., Plaizier J.C., Fievez V. (2013). Grain-based versus alfalfa-based subacute ruminal acidosis induction experiments: Similarities and differences between changes in milk fatty acids. J. Dairy Sci., 96: 4100-4111.

Craninx M., Steen A., Van Laar H., Van Nespen T., Martín-Tereso J., de Baets B., Fievez V. (2008). Effect of lactation stage on the oddand branched-chain milk fatty acids of dairy cattle under grazing and indoor conditions. J. Dairy Sci., 91: 2662-2677.

De Marchi M., Toffanin V., Cassandro M., Penasa M. (2014). Invited review: Mid-infrared spectroscopy as phenotyping tool for milk traits. J. Dairy Sci., 97: 1171-1186.

de Vries M.J., van der Beek S., Kaal-Lansbergen L.M.T.E., Ouweltjes W., Wilmink J.B. (1999). Modeling of energy balance in early lactation and the effect of energy deficits in early lactation on first detected estrus postpartum in dairy cows. J. Dairy Sci., 82: 1927-1934.

Ducháček J., Stádník L., Ptáček M., Beran J., Okrouhlá M., Čítek J., Stupka R. (2014). Effect of cow energy status on the hypercholesterolaemic fatty acid proportion in raw milk. Czech. J. Food. Sci., 32: $273-279$.

Duffield T., Plaizier J.C., Fairfield A., Bagg R., Vessie G., Dick P., Wilson J., Aramini Jand McBride B. (2004). Comparison of techniques for measurement of rumen $\mathrm{pH}$ in lactating dairy cows. J. Dairy Sci., 87: 59-66.

Enjalbert F., Videau Y., Nicot M.C., Troegeler-Meynadier A. (2008). Effects of induced subacute ruminal acidosis on milk fat content and milk fatty acid profile. J. Anim. Physiol. Anim. Nutr., 92: 284-291.

Gottardo P., Penasa M., Righi F., Lopez-Villalobos N., Cassandro M., De Marchi M. (2017). Fatty acid composition of milk from Holstein-Friesian, Brown Swiss, Simmental and Alpine Grey cows predicted by mid-infrared spectroscopy. Ital. J. Anim. Sci., 16: 380-389.

Guo Y., Wang L., Zou Y., Xu X., Li S., Cao Z. (2013). Changes in ruminal fermentation, milk performance and milk fatty acid profile 
in dairy cows with subacute ruminal acidosis and its regulation with pelleted beet pulp. Arch. Anim. Nutr., 67: 433-447.

Hanuš O., Samková E., Křížová L., Hasoňová L., Kala R. (2018). Role of fatty acids in milk fat and the influence of selected factors on their variability - a review. Molecules, 23: 1636.

Hostens M., Fievez V., Leroy J.L.M.R., Van Ranst J., Vlaeminck B., Opsomer G. (2012). The fatty acid profile of subcutaneous and abdominal fat in dairy cows with left displacement of the abomasum. J. Dairy Sci., 95: 3756-3765.

Jing L., Dewanckele L., Vlaeminck B., Van Straalen W.M., Koopmans A., Fievez V. (2018). Susceptibility of dairy cows to sub-acute ruminal acidosis is reflected in milk fatty acid proportions, with C18:1 trans-10 as primary and C15:0 and C18:1 trans-11 as secondary indicators. J. Dairy Sci., 101: 9827-9840.

Kleen J.L., Cannizzo C. (2012). Incidence, prevalence and impact of SARA in dairy herds. Anim. Feed Sci. Technol., 172: 4-8.

Kleen J.L., Upgang L., Rehage J. (2013). Prevalence and consequences of subacute ruminal acidosis in German dairy herds. Acta Vet. Scand., 55: 48.

Krause K.M., Oetzel G.R. (2005). Inducing subacute ruminal acidosis in lactating dairy cows. J. Dairy Sci., 88: 3633-3639.

Kuczyńska B., Puppel K., Gołębiewski M., Kordyasz M., Grodzki H., Brzozowski P. (2012). Comparison of fat and protein fractions of milk constituents in Montbeliarde and Polish Holstein-Friesian cows from one farm in Poland. Acta Vet. Brno, 81: 139-144.

Lock A.L. (2010). Update on dietary and management effects on milk fat. Proc. 19th Annual Tri-State Dairy Nutrition Conference, 15: 26.

Miller N., Delbecchi L., Petitclerc D., Wagner G.F., Talbot B.G., Lacasse P. (2006). Effect of stage of lactation and parity on mammary gland cell renewal. J. Dairy Sci., 89: 4669-4677.

Nordlund K.V., Garrett E.F. (1994). Rumenocentesis: a technique for collecting rumen fluid for the diagnosis of subacute rumen acidosis in dairy herds. Bovine Pract., 28: 109-112.

Proskura W.S., Liput M., Zaborski D., Sobek Z., Yu Y.H., Cheng Y.H., Dybus A. (2019). The effect of polymorphism in the FADS2 gene on the fatty acid composition of bovine milk. Arch. Anim. Breed., 62: $547-555$

Samková E., Špička J., Hanuš O., Roubal P., Pecová L., Hasoňová L., Smetana P., Klimešová M., Cítek J. (2020). Comparison of fatty acid proportions determined by mid-infrared spectroscopy and gas chromatography in bulk and individual milk samples. Animals, 10: 1095 .

Sandri E.C., Lévesque J., Marco A., Couture Y., Gervais R., Rico D.E.
(2020). Transient reductions in milk fat synthesis and their association with the ruminal and metabolic profile in dairy cows fed high-starch, low-fat diets. Animal, 14: 2523-2534.

Stefańska B., Nowak W., Komisarek J., Taciak M., Barszcz M., Skomiał J. (2017 a). Prevalence and consequence of subacute ruminal acidosis in Polish dairy herds. J. Anim. Physiol. Ann., 101: 694-702.

Stefańska B., Pruszyńska-Oszmałek E., Szczepankiewicz D., Stajek K., Stefański P., Gehrke M., Nowak W. (2017 b). Relationship between $\mathrm{pH}$ of ruminal fluid during subacute ruminal acidosis and physiological response of the Polish Holstein-Friesian dairy cows. Pol. J. Vet. Sci., 20: 551-558.

Stefańska B., Człapa W., Pruszynska-Oszmałek E., Szczepankiewicz D., Fievez V., Komisarek J., Stajek K., Nowak W. (2018). Subacute ruminal acidosis affects fermentation and endotoxin concentration in the rumen and relative expression of the CD14/TLR4/ $M D 2$ genes involved in lipopolysaccharide systemic immune response in dairy cows. J. Dairy Sci., 101: 1297-1310.

Stefańska B., Komisarek J., Nowak W. (2020). Noninvasive indicators associated with subacute ruminal acidosis in dairy cows. Ann. Anim. Sci., 20: 1325-1338.

Stoop W.M., Bovenhuis H., Heck J.M.L., van Arendonk J.A.M. (2009). Effect of lactation stage and energy status on milk fat composition of Holstein-Friesian cows. J. Dairy Sci., 92: 1469-1478.

Tao H., Chang G., Xu T., Zhao H., Zhang K., Shen X. (2015). Feeding a high concentrate diet down-regulates expression of ACACA, LPL and SCD and modifies milk composition in lactating goats. PLoS One, 10: e0130525.

Vlaeminck B., Gervais R., Rahman M., Gadeyne F., Gorniak M. Doreau M., Fievez V. (2015). Postruminal synthesis modifies the odd- and branched-chain fatty acid profile from the duodenum to milk. J. Dairy Sci., 98: 1-12.

Vranković L., Aladrović J., Octenjak D., Bijelić D., Cvetnić L., Stojević Z. (2017). Milk fatty acid composition as an indicator of energy status in Holstein dairy cows. Arch. Anim. Breed., 60: 205-212.

Xu T.L., Seyfert H.M., Shen X.Z. (2018). Epigenetic mechanisms contribute to decrease stearoyl-CoA desaturase 1 expression in the liver of dairy cows after prolonged feeding of high-concentrate diet. J. Dairy Sci., 101: 2506-2518.

Received: 10 IX 2020

Accepted: 6 VIII 2021 